\title{
WEIGHTS AND MEASURES
}

On 1 Jan. 1960 following an agreement between the standards laboratories of Great Britain, Canada, Australia, New Zealand, South Africa and the USA, an international yard and an international pound (avoirdupois) came into existence. 1 yard $=91.44$ centimetres; $1 \mathrm{lb} .=453.59237$ grammes.

The abbreviation ' $\mathrm{m}$ ' signifies 'million(s)' and tonnes implies metric tons.

\begin{tabular}{|c|c|c|c|}
\hline \multicolumn{2}{|c|}{ LENGTH } & \multicolumn{2}{|c|}{ Dry Measure } \\
\hline \multirow[t]{2}{*}{$\begin{array}{l}\text { Centimetre } \\
\text { Metre } \\
\text { Kilometre }\end{array}$} & \multirow[t]{2}{*}{$\begin{array}{l}0.394 \text { inch } \\
1.094 \text { yards } \\
0.621 \text { mile }\end{array}$} & $\begin{array}{l}\text { Litre } \\
\text { Hectolitre }\end{array}$ & $\begin{array}{l}0.91 \text { quart } \\
2.75 \text { bushels }\end{array}$ \\
\hline & & \multicolumn{2}{|c|}{ WEIGHT-AVOIRDUPOIS } \\
\hline \multirow{2}{*}{\multicolumn{2}{|c|}{$\begin{array}{lc} & \text { LiQuid MEASURE } \\
\text { Litre } & 1.75 \text { pints } \\
\text { Hectolitre } & 22 \text { gallons }\end{array}$}} & \multirow{2}{*}{$\begin{array}{l}\text { Gramme } \\
\text { Kilogramme } \\
\text { Quintal (= } \\
100 \mathrm{~kg}) \\
\text { Tonne (= } \\
1,000 \mathrm{~kg})\end{array}$} & 15.42 grains \\
\hline & & & $\begin{array}{l}220.46 \text { pounds } \\
0.984 \text { long ton } \\
1.102 \text { short tons }\end{array}$ \\
\hline \multicolumn{2}{|c|}{ Surface Measure } & \multicolumn{2}{|c|}{ WEIGHT-TROY } \\
\hline $\begin{array}{l}\text { Square metre } \\
\text { Hectare } \\
\text { Square kilometre }\end{array}$ & $\begin{array}{l}10.76 \text { sq. feet } \\
2.47 \text { acres } \\
0.386 \text { sq. mile }\end{array}$ & $\begin{array}{l}\text { Gramme } \\
\text { Kilogramme }\end{array}$ & $\left\{\begin{array}{l}15.43 \text { grains } \\
32.15 \text { ounces } \\
2.68 \text { pounds }\end{array}\right.$ \\
\hline
\end{tabular}

\section{BRITISH WEIGHTS AND MEASURES}

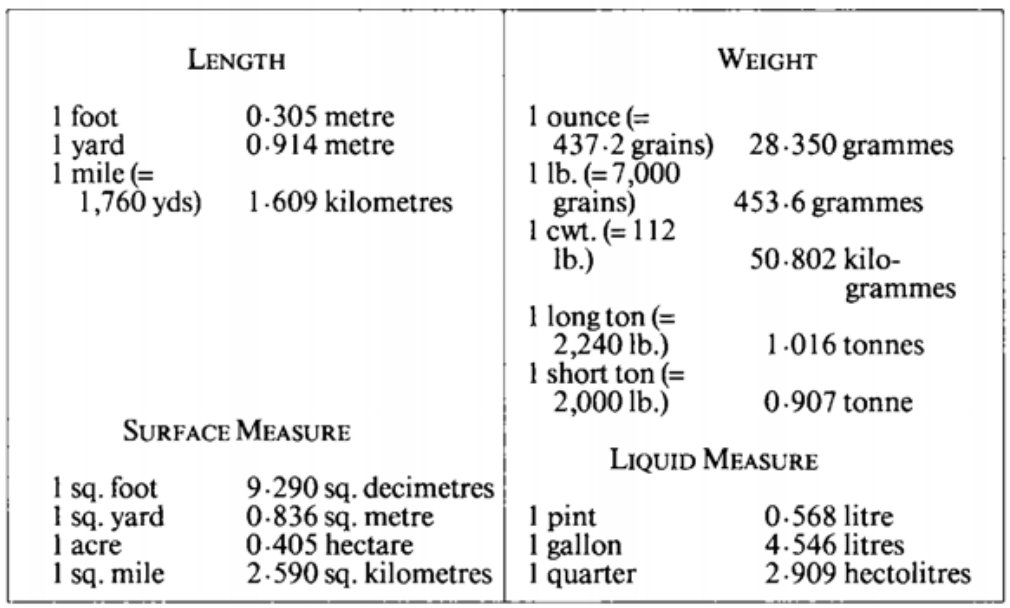

